\title{
An Empirical Study on the Boundary-spanning Search's Impact to the Breakthrough Innovation
}

\author{
Junjie Yin \\ School of Management and Economics, Civil Aviation Flight University of China, \\ Nanchang Road, Guanghan 618307, China \\ yinjunjieuestc@126.com
}

\begin{abstract}
Boundary-spanning search breaks the constraints of the search scope and knowledge structure in the enterprise technology development trajectory, which is the important source for enterprises to gain the competitive advantage. However, studies have not given a reasonable explanation to the problem confronted with the enterprises, how to take advantages of the information and resources to overcome the high degree of uncertainty in the process of breakthrough innovation, and improve the performance. Based on the innovation search theory and resource-based view, we proposed the hypothesis model about boundary-spanning search, strategic flexibility and breakthrough innovation performance. This paper obtained the following key findings: different dimensions of boundary-spanning search have a significantly positive impact on breakthrough innovation performance, strategic flexibility has a significantly positive impact on breakthrough innovation performance, and strategic flexibility as an intermediary variable played a brokering role in the relationship between boundary-spanning search and breakthrough innovation performance.
\end{abstract}

Keywords: Boundary-spanning search, Strategic flexibility, Breakthrough innovation.

\section{Introduction}

At present, the technological revolution and industrial transformation led by the "information society" and "Internet + are gestating and emerging. Global technological innovation is showing new development trends and characteristics, marked by interdisciplinary and technological integration, and new technologies are replacing old technologies. The trend of intelligent technology replacing labor-intensive technology is obvious; actively promoting breakthrough innovation can effectively realize the leap-forward pursuit of enterprises, and fundamentally complete the transition from "follower" to "leader".

Breakthrough innovation is generally considered to lead the direction of technology and industry development, and is the key to enterprises to obtain a winning opportunity and sustainable competitive advantage. However, companies with limited resources and capabilities cannot rely solely on the development of internal knowledge to carry out breakthrough innovations. The level of innovation output of a company depends to a certain extent on the organization's ability to search across boundaries. Information or new knowledge can make up for the lack of internal resources and help companies adapt to the rapid changes in technology and market environments. Scholars have studied the relationship between boundary-spanning search and innovation performance from different perspectives. Rosenkopf and Nerkar found that through boundary-spanning search research on the optical disc industry, crossing organizational boundaries and technological boundaries at the same time has the greatest impact on the technological development of enterprises. The research of Ahuja and Katila shows that scientific search and spatial search have an inverted U-shaped curve relationship with technological innovation. The research results of Phene et al. showed that there is an inverted U-curve relationship between domestic knowledge and knowledge in the field of technology and breakthrough innovation. Foreign knowledge and knowledge in the field of technology have a positive impact on breakthrough innovation; Sidhu et al. taking the technological dynamic environment as a moderating variable, they discussed the impact of different dimensions of boundary-spanning search on enterprise innovation.

At the same time, due to the large number of market, technology, and organizational uncertainties in breakthrough innovation, companies not only need to have the resources and capabilities to carry out breakthrough innovation, but also to be able to effectively combine and allocate innovation resources. Both resource-based theory and enterprise capability theory believe that strategic flexibility, as an ability to enhance organizational resilience and flexibility, is the key to reducing innovation risks and promoting innovation performance. Strategic flexibility reflects the organization's ability to quickly invest resources and deploy resources freely in the process of responding to external changes. On the one hand, this flexibility is manifested in resource flexibility, that is, enterprise resources have a variety of selectivity and applicability, and on the other hand, it is manifested in coordination flexibility, that is, freely configuring resources for various applications. New strategic uses. It can be considered that strategic flexibility is not only the basis for supporting breakthrough innovation activities, but also an accelerator for improving the efficiency and effectiveness of innovation.

Based on the analysis of the above research results, it can be seen that the existing literature mainly discusses the relationship between boundary-spanning search and technological innovation from the dimensions of technical boundary and organizational boundary, and focuses on product innovation. Whether it can make breakthroughs in different dimensions of boundary-spanning search. There are still insufficient researches on the advantages of sexual innovation. On the other hand, there is still a lack of in-depth research on the intermediate paths that boundary-spanning search affects enterprise technological innovation.

Based on this, this article explores the relationship between boundary-spanning search, strategic flexibility and 
breakthrough innovation based on innovative search theory and enterprise resource view. It not only has important practical guiding significance for the improvement of corporate innovation search efficiency and breakthrough innovation, but also And it has certain theoretical value: first, it explores the empirical impact of different dimensions of boundary-spanning search on breakthrough innovation, thereby expanding the research on the influencing factors of breakthrough innovation, and providing a theoretical basis for the smooth development of breakthrough innovation activities of enterprises; second, The relationship between boundary-spanning search and strategic flexibility is explored, and the existing research on strategic flexibility is strongly supplemented and improved, providing a solid theoretical foundation for companies to improve their own strategic flexibility through external search; finally, the cross-border research is proposed. The conceptual model of global search, strategic flexibility and breakthrough innovation helps to understand the formation mechanism of breakthrough innovation, and further enriches the theoretical research of innovation search theory, enterprise resource view and technological innovation

\section{The Theoretical Analysis and Research Hypothesis}

\subsection{Boundary-spanning Search and Breakthrough Innovation}

This study uses the division method of Sidhu et al. to divide boundary-spanning search into three types: Supply-side search refers to the search for related knowledge and information such as product design and production technology across different knowledge and technical fields. Increase the knowledge stock of products and their production; demand-side search emphasizes the search for knowledge and information related to product marketing, market status and prospects, so as to enhance the ability of enterprises to discover and utilize opportunities; spatial search refers to the geographical area of the organization Search for knowledge and information related to technology and market.

\section{(1) Supply-side search and breakthrough innovation}

It is difficult for companies to successfully develop new technologies only by relying on their own capabilities. The exploration of new knowledge elements or the "recombination" of existing knowledge elements is an important way for companies to break through innovation, which requires companies analyze the technical knowledge of different fields and industries, and complement the enterprise's own marketing, R\&D, design, or manufacturing.

Supply-side search can enable companies to cross the original technological boundaries and obtain complementary technical knowledge and related resource capabilities (such as technology research and development resources, product manufacturing skills, production processes, and technology development trends, etc.) from the outside. Through the integration of heterogeneous technical knowledge, the possibility of integration and reorganization between internal and external knowledge of the enterprise is increased, which will help the enterprise to break through the original technological track and develop breakthrough products that are difficult for competitors to imitate. More importantly, with the rapid transformation of technology paradigm and the shortening of product life cycle, supply-side search reduces the time lag for companies to detect cutting-edge and emerging technologies through patents, publications, etc., and enhances breakthrough innovation activities. Reliability, reducing learning costs and avoiding potential test errors make it easier to surpass the current mainstream technology development level and lay the technical foundation for the success of enterprise breakthrough innovation. Based on the above analysis, this article proposes the following hypotheses:

Hypothesis H1a: There is a positive correlation between supply — side search and breakthrough innovation.

\section{(2)Demand-side search and breakthrough innovation}

Demand-side search refers to searching for new market segments, product design, distribution channels, and business models across the organization's accumulated experience in the existing product market to better understand customer needs and preferences. When Christensen studied how Honda entered and occupied the US market, he confirmed that the company's attention to external market information is the key to successful development of breakthrough technologies. Demand-side search emphasizes the discovery and prediction of unsatisfied potential markets, and the big data obtained from this can deepen the enterprise's understanding of existing market needs: on the one hand, it can promote the generation of new ideas and ideas, and then inspire the enterprise Carrying out more technological explorations and changes to provide opportunities for breakthrough innovation activities; on the other hand, it ensures that innovation activities are highly consistent with market needs, avoids repeated innovation activities, and can be better than competitors and customers. Develop new processes and technologies, and introduce new products and services to meet or exceed the current market's pursuit of technical performance.

Therefore, in the process of breakthrough innovation, demand-side search not only helps companies understand current and potential customer needs through market research, but also helps companies evaluate and predict changes in the business environment at any time, and have more opportunities to develop new ones. Based on the above analysis, this article proposes the following hypotheses:

Hypothesis H1b: There is a positive correlation between demand-side search and breakthrough innovation

\section{(3) Spatial search and breakthrough innovation}

As technical knowledge tends to be specialized, regionalized, and spatially agglomerated, different countries have different technical advantages. In the process of spatial search, companies can access specific resources in different countries, discover and obtain complementary knowledge necessary for breakthrough innovation, enrich the internal knowledge base 
of the company, and facilitate the combination and innovation of new knowledge and original knowledge. Moreover, these resources and knowledge may be under-supply in the home country of the enterprise, avoiding excessive dependence on local resources and knowledge, and preventing itself from being locked in the existing technological track. In addition, spatial search can enable companies to discover potential emerging markets. These new market demands provide opportunities for breakthrough innovations, and companies can develop corresponding new products for specific market needs. Therefore, geo-side search provides an opportunity to break the self-confidence of enterprises, promote the flow and dissemination of heterogeneous resources and knowledge within the network, and contribute to the breakthrough innovation activities of enterprises. Based on the above analysis, this article proposes the following hypotheses:

Hypothesis H1c: There is a positive correlation between spatial search and breakthrough innovation

\subsection{Boundary-spanning Search and Strategic Flexibility}

Combining the views of Shimizu and Hitt, we believe that strategic flexibility means that companies respond quickly to market opportunities or threats in an active or reactive manner, coordinate changes with the external environment, adjust strategic decisions in time, reorganize resources flexibly, and overcome path dependence. Dynamic ability to achieve corporate goals. Most scholars also widely recognize that strategic flexibility is composed of resource flexibility and coordination flexibility. The following will study the impact of boundary-spanning search on strategic flexibility according to different dimensions.

\section{(1) Supply-side search and strategic flexibility}

The high-level Supply-side search increases the interactive activities between the enterprise and external partners, which is conducive to the transfer of technical information and resources across organizational boundaries. The enterprise can more fully grasp the technical information of the product, which provides an opportunity for the enterprise to expand the scope and use innovative resources. In addition to the conditions, it also increases the possibility and convenience of its use conversion, and then it can be considered that the flexibility of its external innovation resources is higher. In addition, while companies obtain complementary technical knowledge through supply-side search, they also provide guidance on the direction of innovative resource use for themselves. In the process of Supply-side search, companies can compare the acquired information and resources, think about their own business operations and product innovation processes, and use this knowledge to improve their own shortcomings, so as to how to use their own resources to respond to external changes. Provided support. It can be seen that the Supply-side search has a positive impact on the use and allocation of the enterprise's own innovation resources. Based on the above analysis, this article puts forward the following hypotheses:

Hypothesis H2a: There is a positive correlation between supply-side search and resource flexibility
Hypothesis H3a: There is a positive correlation between supply-side search and coordination flexibility.

\section{(2) Demand-side search and strategic flexibility}

As mentioned above, the demand-side search not only emphasizes the needs expressed by customers, but also pays attention to the unsatisfied potential needs of the market, so that companies can obtain market information and knowledge that are closely related to breakthrough innovations. This information and knowledge can help companies accurately and quickly grasp the market direction, clarify the focus of technological R\&D and innovation, and the proportion of scientific investment, which in turn helps companies to flexibly use and allocate innovative resources. The more information and knowledge an enterprise has, the greater the possibility of the organization's formation and maintenance of flexibility, and the quicker and more proactive it is to respond to the high uncertainty of breakthrough innovation. It can be seen that demand-side search can prompt companies to obtain market information and knowledge that is highly compatible with innovation, and increase the possibility of efficient coordination and resource allocation, thereby continuously consolidating and improving the strategic flexibility of the organization, creating benefits for companies' breakthrough innovation activities. Based on the above analysis, this article proposes the following hypotheses:

Hypothesis H2b: There is a positive correlation between demand-side search and resource flexibility

Hypothesis H3b: There is a positive correlation between demand-side search and coordination flexibility

\section{(3) Spatial search and strategic flexibility}

Spatial search focuses on the differences in the regional application scenarios of technical knowledge, and emphasizes the search for new technologies, new products, new methods and other knowledge related to technical knowledge across the geographic area of the organization. Therefore, spatial search provides enterprises with new knowledge distribution, and enterprises have more channels and opportunities to obtain information and knowledge resources, which is convenient for mining and integrating scientific and technological resources distributed all over the world. With the deepening of spatial search, the various markets and cultural environments that companies are exposed to can also promote their own learning, and their understanding of original resources will gradually deepen, which will help the efficient use of innovative resources. When an enterprise responds to the needs of the international market, its products can better adapt to the needs and preferences of international users, and improve the response speed and adaptability to the market. Therefore, spatial search can allow new knowledge to enter, making organizations more flexible in uncertain environments, and laying a foundation for improving strategic flexibility. Based on the above analysis, this article proposes hypotheses:

Hypothesis H2c: There is a positive correlation between spatial search and resource flexibility

Hypothesis $\mathrm{H} 3 \mathrm{c}$ : There is a positive correlation between spatial search and coordination flexibility 


\subsection{Strategic Flexibility and Breakthrough Innovation}

Breakthrough innovation activities are the process of recombination of corporate resources and capabilities, which are characterized by uncertainty, destructiveness and discontinuity. In this process, the company's resources and capabilities will be recombined through new organizational methods. The two dimensions of strategic flexibility (resource flexibility and coordination flexibility) precisely reflect the characteristics of the corresponding innovation resources and capabilities of the enterprise, so as to better ensure that the enterprise carries out effective breakthrough innovation activities.

Resource flexibility refers to the flexibility of the company's existing resources, the availability of idle resources, and the creation and accumulation of potential resources. Coordination flexibility reflects the company's ability to identify, configure, and deploy existing resources. For breakthrough technological innovations with very high uncertainty, resource flexibility is a buffer for enterprises to adapt to external dynamic changes. The higher the level of resource flexibility, the stronger the compatibility between various innovative resources, and the easier it is for enterprises to cope with possible changes at any time. Uncertainty factors appearing; coordination flexibility helps companies adjust resources and optimize allocation to respond to changes in breakthrough innovation activities, and achieve the best combination of various resources. Breakthrough innovation is a disruptive and discontinuous innovation activity. Enterprises with high strategic flexibility can make short-term and rapid adjustments to the products they produce or provide, shorten the reaction time to deal with the uncertainty in the process of breakthrough innovation, and make it easier Timely adjust the use of existing resources or organize new resources to invest in breakthrough innovations to maximize existing resources and enhance the ability of enterprises to adapt to changes in breakthrough innovation activities. Based on the above analysis, this article proposes the following hypotheses:

Hypothesis H4a: There is a positive correlation between resource flexibility and enterprise breakthrough innovation Hypothesis H4b: There is a positive correlation between coordination flexibility and corporate breakthrough innovation

Based on the above assumptions, the conceptual model of this research is shown in Figure 1.

H1a

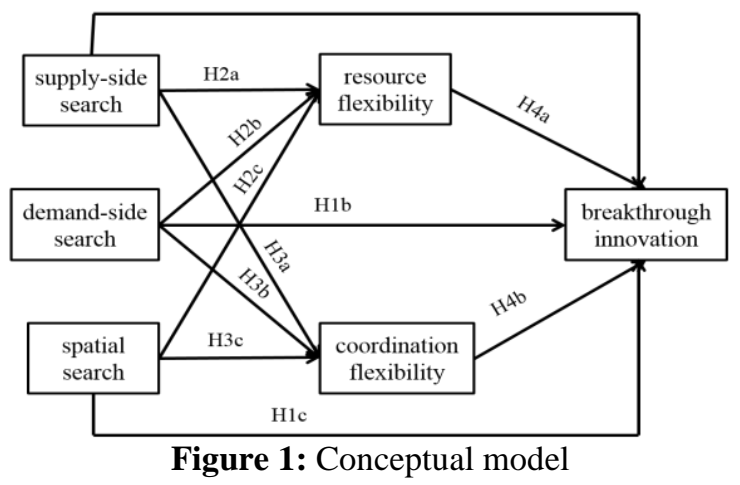

\section{Research Design}

\subsection{Sample Selection and Data Collection}

The research samples come from questionnaire survey data of high-tech enterprises in Chengdu High-tech Industrial Development Zone and Wuxi (Taihu) International Science and Technology Park. The reason for choosing the companies in these two industrial parks as the research objects is that the parks contain large and medium-sized enterprises engaged in strategic emerging industries such as new-generation information technology, bio-industry, and high-end equipment manufacturing industries, and their industries have short technical life cycles and resource The degree of dependence is high, boundary-spanning searches by enterprises are very common, and breakthrough innovation activities occur from time to time, which helps to enhance the reliability and representativeness of data collection. In order to ensure the response rate of the questionnaire, the questionnaire was distributed and collected with the help of the senior managers of the two industrial parks. The questionnaire was mainly filled out by the middle and senior managers of the enterprise. A total of 370 questionnaires were issued this time, 292 were returned, 84 invalid questionnaires were screened out, and 208 valid questionnaires were finally obtained. The effective rate of the returned questionnaires was $71.2 \%$.

A non-response bias test is performed on the sample of the questionnaire collected. According to the order of recovery, the questionnaire was divided into two groups, and the t-test was performed on the enterprise size and age of the two samples. The results showed that there was no significant difference between the two parts of the questionnaire at the 0.05 level. The non-response bias of the questionnaire is not serious. In addition, since all items in the questionnaire survey are filled out by the same person, it may cause deviations from the same source method. The questionnaire carried out the Harman single factor test, which puts boundary-spanning search, strategic flexibility, and breakthrough innovation together for exploratory factor analysis. The unrotated factor analysis results show that there is no common factor in the factor structure, and the first one. The factor only explained $16.72 \%$ of the variation. Therefore, it can be inferred that there is no common method deviation.

\subsection{Variable Measurement}

In order to ensure the validity and reliability of the measurement, we comprehensively combed the research results of domestic and foreign scholars, designed the measurement table of this article based on the research characteristics of this article and the actual situation of the survey subjects, and used Likert's 5-level score for the measurement. Law. The boundary-spanning search mainly refers to the measurement method of Sidhu et al., in which there are 6 items in the supply-side, 6 items in the demand-side, and 4 items in the spatial dimension; the strategic flexibility mainly refers to Yuan et al. and Sanchez, the scale used by Zhou and $\mathrm{Wu}$, including 4 items of resource flexibility, 4 items of coordination flexibility, 8 items in total; breakthrough innovation draws on the research table of Subramaniam and Youndt, set 3 items. 
In terms of control variables, company age, company size, and R\&D investment intensity are the main control variables. Among them, the age of the company is measured by the difference between the questionnaire collection year and the year the company was founded; the scale of the company is measured by the natural logarithm of the total number of employees; the intensity of R\&D investment is measured by the ratio of the company's $R \& D$ investment to sales revenue in the current year.

\section{Empirical Analysis}

\subsection{Reliability and Validity Test}

The data involved in this research has been tested for reliability through SPSS19.0 software. We calculated the Cronbach's a coefficient and composite reliability (CR) of all variables separately. As shown in Table 1, the a coefficient and $\mathrm{CR}$ of all the latent variables exceeded 0.7 , indicating that the scale has good internal consistency. The variables used in the study have high reliability.

In the validity test, the research items are all derived from the feasibility of the questionnaire design in the research of other scholars, combined with the actual research questions and consulting relevant experts to revise part of the questionnaire, so the questionnaire has high content validity. In addition, the factor loadings of the measurement items are all above 0.7 , and the average extraction variance (AVE) is all greater than 0.5 , indicating that the constructs in this study have good aggregate validity. Therefore, the scale used in this study has good reliability and validity, and can be used for further analysis of the relationship between the various variables.

\subsection{Descriptive Statistics and Correlation Analysis}

Table 1 shows the descriptive statistics of each variable, including the mean, standard deviation, and the correlation coefficient between the variables. It can be seen from the descriptive statistical analysis of the variables that through data analysis, it can be found that the correlation coefficient of each variable is not greater than 0.7 , that is, there is no potential collinearity problem between the variables; boundary-spanning search, strategic flexibility and breakthrough innovation There is a significant positive correlation between the latent variables to which the three constructs belong.

Table 1: Variable correlatione

\begin{tabular}{|c|c|c|c|c|c|c|c|c|c|}
\hline Variable & 1 & 2 & 3 & 4 & 5 & 6 & 7 & 8 & 9 \\
\hline \multicolumn{10}{|l|}{ 1. Supply-side search } \\
\hline 2. Demand-side search & $0.384 * *$ & & & & & & & & \\
\hline 3. spatial search & $0.275^{* *} *$ & $0.358 * *$ & & & & & & & \\
\hline 4. Resource flexibility & $0.158 * *$ & $0.230 * *$ & $0.174 * *$ & & & & & & \\
\hline 5. Coordination flexibility & $0.227 * *$ & $0.307 *$ & $0.011 * *$ & $0.467 * *$ & & & & & \\
\hline 6. Breakthrough innovation & $0.194 * *$ & $0.225 * *$ & $0.236^{*}$ & $0.285 * *$ & $0.473 *$ & & & & \\
\hline 7. Business age & 0.052 & 0.026 & -0.164 & 0.359 & 0.118 & -0.192 & & & \\
\hline 8. Enterprise scale & 0.121 & 0.063 & 0.290 & 0.307 & 0.246 & -0.282 & $0.358^{*}$ & & \\
\hline 9. R\&D investment intensity & $0.046 *$ & $0.148 *$ & 0.135 & -0.052 & 0.081 & 0.247 & 0.127 & -0.294 & \\
\hline Mean & 3.272 & 3.117 & 2.459 & 3.507 & 3.035 & 3.845 & 12.46 & 2.64 & 0.083 \\
\hline Standard deviation & 1.459 & 1.723 & 1.324 & 0.972 & 1.260 & 1.058 & 6.312 & 2.114 & 0.592 \\
\hline
\end{tabular}

$$
\text { *** } \mathrm{p}<0.01, * * \mathrm{p}<0.05, * \mathrm{p}<0.1
$$

\subsection{Structural Equation Model Analysis}

AMOS 17. 0 was used to construct a structural equation model to analyze the relationship structure between latent variables to further verify the research hypothesis.

The core logic of the theoretical conceptual model of this paper is that boundary-spanning search affects the breakthrough innovation of enterprises through the mediating effect of strategic flexibility. According to the principle of mediating effect, there is a significant influence relationship between independent variables and dependent variables, which is a prerequisite for the analysis of mediating effect of strategic flexibility. Therefore, between the initial model construction, it is necessary to analyze the impact relationship between boundary-spanning search and breakthrough innovation. By establishing a structural equation model for boundary-spanning search to influence breakthrough innovation, it can be concluded that the three constituent variables of boundary-spanning search have significant positive effects on breakthrough innovation. As shown in Table 2, the relevant fitting indexes of the model meet the requirements, indicating that the model fits well.

Table 2: Main effect hypothesis fitting results

\begin{tabular}{|c|c|c|c|c|c|c|c|}
\hline \multicolumn{4}{|c|}{ Hypothetical path } & \multicolumn{2}{|c|}{ Standardized path coefficient } & C.R. & $\bar{P}$ \\
\hline \multicolumn{4}{|c|}{ H1a:breakthrough innovation $\leftarrow$ Supply-side search } & \multicolumn{2}{|c|}{0.576} & 4.462 & **** \\
\hline \multicolumn{4}{|c|}{ H1b:breakthrough innovation $\leftarrow$ Demand-side search } & \multicolumn{2}{|c|}{0.348} & 4.065 & **** \\
\hline \multicolumn{4}{|c|}{ H1c:breakthrough innovation $\leftarrow$ Spatial search } & \multicolumn{2}{|c|}{0.249} & 3.677 & 0.003 \\
\hline Fitting index & $\chi^{2} / \mathrm{df}$ & RMSEA & GFI & AGFI & NFI & CFI & TLI \\
\hline Numerical value & 1.948 & 0.054 & 0.912 & 0.910 & 0.907 & 0.935 & 0.956 \\
\hline
\end{tabular}

Under this premise, we constructed an initial structural equation model for the impact of boundary-spanning search on the breakthrough innovation of enterprises. The results showed that some of the main model fitting indexes of the initial structural equation model did not meet the model fitting requirements. Therefore, we first fine-tune the residuals of the measurement indicators according to the correction index, adjust only one parameter at a time, and delete the paths with insignificant $P$ values and C.R. values significantly lower than 1.96. Through multiple revisions and comparisons of the initial model, the final model has a good fit, so the path model can be accepted. The revised model path and results are shown in Figure 2 and Table 3. 


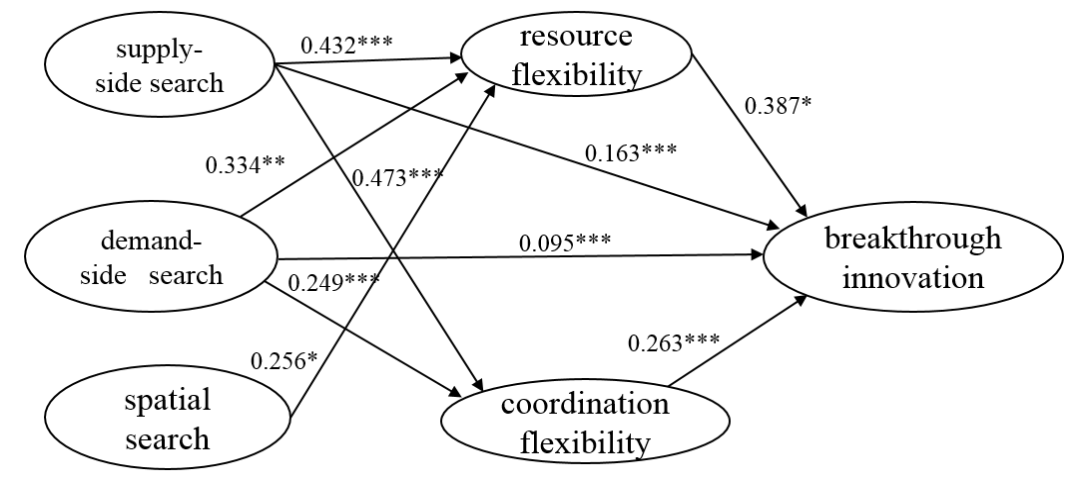

Figure 2: Path diagram of AMOS output model (standardized coefficient)

Table 3: Structural equation correction model analysis results

\begin{tabular}{|c|c|c|c|c|c|c|c|}
\hline \multicolumn{2}{|c|}{ Hypothetical path } & \multicolumn{2}{|c|}{ Standardized path coefficient } & \multicolumn{2}{|c|}{ C.R. } & \multicolumn{2}{|c|}{$\mathrm{P}$} \\
\hline \multicolumn{2}{|c|}{ resource flexibility $\leftarrow$ supply-side search } & \multicolumn{2}{|c|}{0.432} & \multicolumn{2}{|c|}{4.532} & \multicolumn{2}{|c|}{ **** } \\
\hline \multicolumn{2}{|c|}{ coordination flexibility $\leftarrow$ supply-side search } & \multicolumn{2}{|c|}{0.473} & \multicolumn{2}{|c|}{4.225} & \multicolumn{2}{|c|}{$* * *$} \\
\hline \multicolumn{2}{|c|}{ resource flexibility $\leftarrow$ demand-side search } & \multicolumn{2}{|c|}{0.334} & \multicolumn{2}{|c|}{3.489} & \multicolumn{2}{|c|}{0.004} \\
\hline \multicolumn{2}{|c|}{ coordination flexibility $\leftarrow$ demand-side search } & \multicolumn{2}{|c|}{0.249} & \multicolumn{2}{|c|}{5.272} & \multicolumn{2}{|c|}{ **** } \\
\hline \multicolumn{2}{|c|}{ coordination flexibility $\leftarrow$ spatial search } & \multicolumn{2}{|c|}{0.256} & \multicolumn{2}{|c|}{3.127} & \multicolumn{2}{|c|}{0.017} \\
\hline \multicolumn{2}{|c|}{ breakthrough innovation $\leftarrow$ supply-side search } & \multicolumn{2}{|c|}{0.163} & \multicolumn{2}{|c|}{3.400} & \multicolumn{2}{|c|}{ **** } \\
\hline \multicolumn{2}{|c|}{ breakthrough innovation $\leftarrow$ demand-side search } & \multicolumn{2}{|c|}{0.095} & \multicolumn{2}{|c|}{4.786} & \multicolumn{2}{|c|}{ **** } \\
\hline \multicolumn{2}{|c|}{ breakthrough innovation $\leftarrow$ resource flexibility } & \multicolumn{2}{|c|}{0.387} & \multicolumn{2}{|c|}{2.471} & \multicolumn{2}{|c|}{0.021} \\
\hline \multicolumn{2}{|c|}{ breakthrough innovation $\leftarrow$ coordination flexibility } & \multicolumn{2}{|c|}{0.263} & \multicolumn{2}{|c|}{3.832} & & \\
\hline Indexes of fitting & $\chi^{2} / \mathrm{df}$ & RMSEA & GFI & AGFI & NFI & $\mathrm{CFI}$ & TLI \\
\hline Vaule & 2.145 & 0.063 & 0.901 & 0.916 & 0.932 & 0.958 & 0.949 \\
\hline
\end{tabular}

\subsection{Analysis of Results}

The three dimensions of boundary-spanning search have a significant positive impact on the company's breakthrough innovation. Hypothesis H1a, Hypothesis H1b, and Hypothesis 1c have been verified; the Supply-side search significantly affects resource flexibility $(0.432 * * *)$ and coordination flexibility $(0.473 * *)$, and has a greater impact on coordination flexibility, assuming that $\mathrm{H} 2 \mathrm{a}$ and $\mathrm{H} 3 \mathrm{a}$ pass the verification; demand-side search significantly affects resource flexibility $(0.334 * *)$ and coordination flexibility $(0.249 * * *)$, but has a large impact on resource flexibility, Assuming $\mathrm{H} 2 \mathrm{~b}$ and $\mathrm{H} 3 \mathrm{~b}$ are verified; spatial search has a significant positive impact on coordination flexibility $\left(0.256^{*}\right)$, but the impact on resource flexibility is not significant, assuming $\mathrm{H} 3 \mathrm{c}$ is verified, and assuming $\mathrm{H} 2 \mathrm{c}$ fails; resource flexibility and coordination flexibility are related to the enterprise The breakthrough innovation is significantly positively correlated (standardized path coefficients are $0.387 * * *, 0.263 * *$, respectively) Hypothesis H4a and Hypothesis H4b have been verified.

In order to more clearly illustrate the full impact of the conceptual model path, the direct and indirect effects between the variables are calculated. The direct effect of supply-side search on enterprise's breakthrough innovation is 0.163 , and the indirect effect is 0.291 ; the direct effect of demand-side search on enterprise's breakthrough innovation is 0.095 , and the indirect effect is 0.194 . This shows that this shows that supply-side search and demand-side search have a role in promoting breakthrough innovation of enterprises, and indirectly promotes breakthrough innovation of enterprises through strategic flexibility (including resource flexibility and coordination flexibility). Spatial search has no direct impact on the company's breakthrough innovation, but indirectly affects the company's breakthrough innovation through the coordination and flexibility of the intermediary.

\section{Conclusion and Inspiration}

The thesis constructs a theoretical framework with boundary-spanning search as the independent variable, strategic flexibility as the intermediary variable, and corporate breakthrough innovation as the dependent variable. The proposal and empirical test of this theoretical framework not only make up for the lack of research on the internal mechanism of the relationship between boundary-spanning search and corporate breakthrough innovation, but also further clarify the path of boundary-spanning search for corporate breakthrough innovation, which is important for innovation search. The enrichment and improvement of theories have played a positive role in promoting, and at the same time, it is a beneficial supplement to the research on breakthrough innovation of enterprises, laying the foundation for follow-up research.

The demand-side, Supply-side and spatial search in the boundary-spanning search have a significant positive impact on the breakthrough innovation of enterprises. This conclusion is consistent with the point of view of the open innovation theory. Open innovation emphasizes the importance of external resources and information, and obtains the complementary and heterogeneous resources and information needed through focused and targeted search strategies. The logical starting point for breakthrough innovation and technological leapfrogging. The search across technology, market, and geographic boundaries has promoted the optimization of organizational strategic flexibility and promoted the growth of breakthrough technological capabilities within the enterprise. This provides a theoretical basis for companies to improve breakthrough innovation performance in an open innovation environment: that is, companies should focus on boundary-spanning search activities from a strategic level, strengthen the exploration of new technologies, new markets and new regions, and actively 
and extensively search for and use external Resources and information, thereby effectively improving the company's breakthrough innovation performance.

The improvement of strategic flexibility can reduce the cost of resource transfer of enterprises, improve the efficiency of resource utilization and allocation, thereby enhancing the ability to deal with the uncertainty in breakthrough innovation activities. Therefore, making full use of the advantages of boundary-spanning search and actively searching for domestic and foreign scientific and technological resources and market resources to improve their own resource flexibility and coordination flexibility is an important strategic choice for companies to improve their breakthrough innovation performance. The positive effect of boundary-spanning search on enterprise's breakthrough innovation is achieved to a large extent by improving resource flexibility and coordination flexibility, and the positive effect of supply-side search and demand-side search is greater than that of geographic-side search.

At present, technological innovation is showing unprecedented power. Innovations based on breakthrough technological innovation are emerging in endlessly, and competition among enterprises is becoming increasingly fierce. Through the cultivation and development of strategic flexibility, the company's ability to allocate and utilize existing resources is enhanced, the negative impact of the uncertainty of breakthrough innovation on the company is minimized, and the performance of breakthrough innovation is improved, which is a sustainable competitive advantage for the company key.

\section{References}

[1] M K. Srivastava, D R. Gnyawali, "When do relational resources matter? Leveraging portfolio technological resources for breakthrough innovation," Academy of Management Journal, 54(4): 797-810, 2011.

[2] D J. Miller, M J. Fern, L B. Cardinal, "The use of knowledge for technological innovation within diversified firms," Academy of Management Journal, 50(2): 307-325, 2007.

[3] R. Kotha, Y. Zheng, G. George, "Entry into new niches: the effects of firm age and the expansion of technological capabilities on innovative output and impact," Strategic Management Journal, 32(9): 1011-1024, 2011.

[4] L. Rosenkopf, A. Nerkar, "Beyond local search: boundary-spanning, exploration, and impact in the optical disk industry," Strategic Management Journal, 22(4): 287-306, 2001.

[5] G. Ahuja, R. Katila, "Where do resources come from? The role of idiosyncratic situations," Strategic Management Journal, 25(8-9): 887-907, 2004.

[6] A. Phene, K. Fladmoe-lindquist, L. Marsh, "Breakthrough innovations in the US biotechnology industry: The effects of technological space and geographic origin," Strategic Management Journal, 27(4): 369-388, 2006.
[7] J S. Sidhu, H R. Commandeur, H W. Volberda, "The multifaceted nature of exploration and exploitation: value of supply, demand, and spatial search for innovation," Organization Science, 18(1): 20-38, 2007.

[8] W. Schoenmakers, G. Duysters, "The technological origins of radical inventions," Research Policy, 39(8): 1051-1059, 2010.

[9] L. Yuan, Zhongfeng, L. Yi, "Can strategic flexibility help firms profit from product innovation?" Technovation, 30(5): 300-309, 2010.

[10] H H. Lee, T T. Yang, C R. Li, "How does boundary-spanning search matter in China's new technology venture? The role of external relationship and internal competence," African Journal of Business Management, 5(20): 8256-8269, 2011.

[11] C J. lin, C R.li, "The effect of boundary-spanning search on breakthrough innovations of new technology ventures," Industry and Innovation, 20(2): 93-113, 2013

[12] C. Grimpe, W. Sofka, "Search patterns and absorptive capacity: low-and high-technology sectors in European countries," Research policy, 38(3): 495-506, 2009.

[13] J. Howells, "Intermediation and the role of intermediaries in innovation," Research policy, 35(5): 715-728, 2006.

[14] B J. Jaworski, A K. Kohli, "Market orientation: antecedents and consequences," The Journal of Marketing, 53-70, 1993.

[15] V. Govindarajan, P K. Kopalle, E. Danneels, "The effects of mainstream and emerging customer orientations on radical and disruptive innovations," Journal of Product Innovation Management, 28(s1): 121-132, 2011

[16] B. Mcevily, A. Marcus, "Embedded ties and the acquisition of competitive capabilities," Strategic Management Journal, 26(11): 1033-1055, 2005.

[17] M L. Santos-Vijande, J Á. López-Sánchez, J A. Trespalacios, "How organizational learning affects a firm's flexibility, competitive strategy, and performance," Journal of Business Research, 65(8): 1079-1089, 2012.

[18] D. Lavie, S R. Miller, "Alliance portfolio internationalization and firm performance," Organization Science, 19(4): 623-646, 2008.

[19] Y H. Chiang, K P. Hung, "Exploring open search strategies and perceived innovation performance from the perspective of inter-organizational knowledge flows," R\&D Management, 40(3): 292-299, 2010.

[20] R. Sanchez, "Preparing for an uncertain future: managing organizations for strategic flexibility," International Studies of Management \& Organization, 27(2): 71-94, 1997.

[21] K Z. Zhou, F. Wu, “Technological capability, strategic flexibility, and product innovation," Strategic Management Journal, 31(5): 547-561, 2010.

[22] K P. Yang, C. Chou, Y J. Chiu, "How unlearning affects radical innovation: the dynamics of social capital and slack resources," Technological Forecasting and Social Change, 87: 152-163, 2014.

[23] M. Subramaniam, M A. Youndt, "The influence of intellectual capital on the types of innovative capabilities," Academy of Management Journal, 48(3): 450-463, 2005. 


\section{Author Profile}

Jjunjie Yin received Ph.D. in management from the University of Electronic Science and Technology of China in 2018. And he is currently mainly engaged in the research of technological innovation management. 